\title{
PROBLEMATIKA AKIDAH DI ERA GLOBALISASI
}

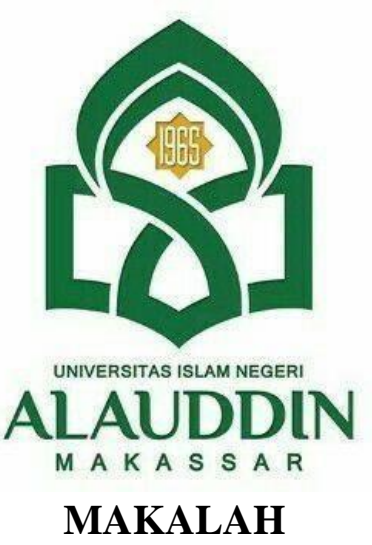

Di Seminarkan Pada Mata Kuliah Aidah Akhlak Program Studi Perbankan Syariah Semester I Tahun 2021

Oleh:

MUH ARFIAN ARIFIN

NIM: 90500121023

Dosen Pengajar:

SUPRIADI HAMID,S.E.I,M.E,I.

\section{PROGRAM STUDI PERBANKAN SYARIAH \\ FAKULTAS EKONOMI DAN BISNIS ISLAM UIN \\ ALAUDDIN MAKASSAR}

2021

KATA PENGANTAR 


\section{然}

Puji syukur penulis panjatkan ke hadirat Allah swt. Atas rahmat dan hidayah-Nya sehingga penyusunan tesis ini dapat diselesaikan. Shalawat dan salam semoga tercurahkan kepada Nabi Mauhammad saw, keluarga dan para sahabatnya. tesis dengan judul:" PROBLEMATIKA AKIDAH DI ERA GLOBALISASI " ini dimaksudkan untuk memenuhi salah satu tugas pada mata kuliah akidah akhlak. Penulis menyadari bahwa penyelesaian tesis ini tidak akan terwujud tanpa bantuan, bimbingan dan dukungan dari berbagai pihak.

Makassar, 28 November 2021

Penyusun

RESKI AWALIA

DAFTAR ISI

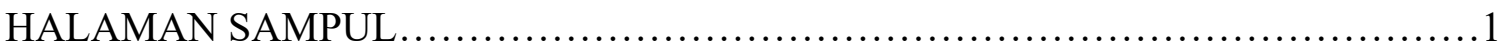

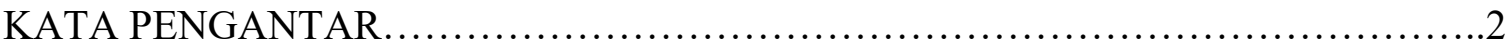

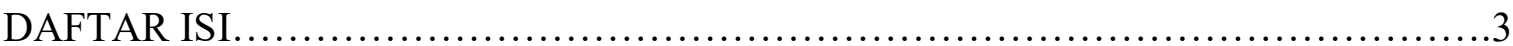




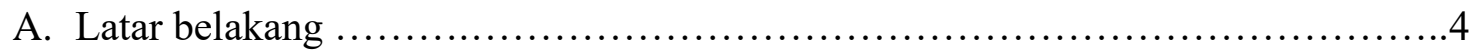

B. Rumusan Masalah......................................................... 4

C. Tujuan Penelitian........................................................ 5

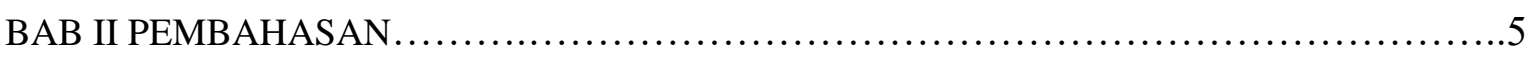

Pengertian akidah dan globalisasi.................................................5

Pengaruh globalisasi terhadap akidah muslim masa kini...........................6

Cara mempertahankan akidah di era globalisasi......................................8

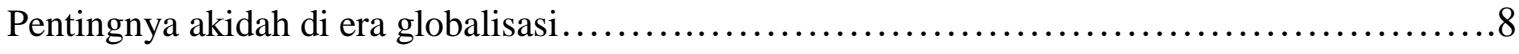

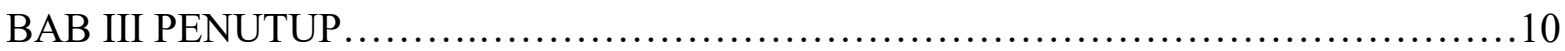

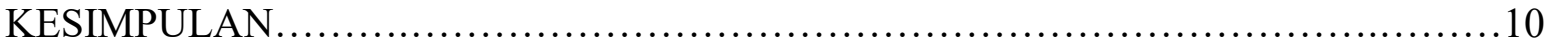

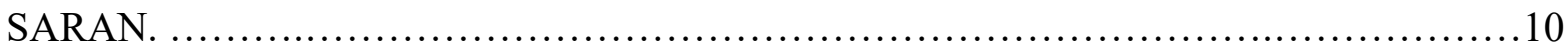

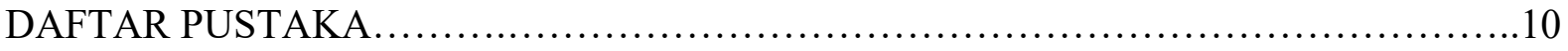

\section{BAB I PENDAHULUAN}

\section{A.Latar Belakang}

Dalam era globalisasi seperti sekarang ini dapat digambarkan bahwa masyarakat dunia semakin dinamis dan komplek dikarenakan adanya penemuan-penemuan di bidang ilmu pengetahuan dan teknologi. Contoh nyata dari fenomena di atas adalah terbukanya komunikasi tanpa batas antara dunia barat dunia timur yang berdampak pada kemajuan dan adanya saling tukar menukar informasi dengan cepat. Dengan adanya kemajuan dalam segala bidang tersebut, segala sesuatu akan lebih mudah dan efisien, sehingga seolah-olah menuntut manusia untuk bersikap terbuka dengan adanya perkembangan dan kemajuan dunia tersebut. Hal ini berdampak positif bagi manusia pada umumnya, karena dengan terbukanya komunikasi dan informasi memudahkan manusia mendapatkan informasi-informasi aktual dengan cepat dan hanya sedikit hambatan. Perkembangan teknologi ini selain mempunyai manfaat ternyata membawa imbas negatif yang disebabkan oleh budaya asing yang menyesatkan, sehingga menimbulkan kemerosotan norma-norma dalam kehidupan masyarakat. Kebobrokan moral, penyakit rohani, serta bentuk penyimpangan lainnya kini telah merebak dalam masyarakat Indonesia, khususnya generasi muda. Mereka lebih mementingkan urusan duniawi daripada urusan akhirat. 2 Contoh penyimpangan itu adalah: perjudian yang merajalela, perampokan, pencurian, serta pergaulan bebas. Disamping itu, bentuk 
penyimpangan yang sangat meresahkan bangsa Indonesia adalah adanya barang haram berupa narkoba. Barang ini selain dilarang oleh agama Islam merupakan salah satu penyebab rusaknya akhlak, khususnya ganerasi muda penerus bangsa.

\section{B. Rumusan Masalah}
A. Apa yang di maksud akidah dan globalisasi?
B. Apa saja pengaruh globalisasi terhadap akidah umat islam masa kini?
C. Bagaimana Cara mempertahankan akidah di era globalisasi ?
D. Mengapa akidah penting di era globalisasi?

\section{C.Tujuan}

A. Untuk mengetahui defenisi akidah dan globalisasi

B. Untuk mengetahui pengaruh globalisasi terhadap akidah umat islam masa kini

C. Untuk mengetahui cara mempertahankan akidah di era globalisasi

D. Untuk mengetahui pentingnya akidah di era globalisasi bagi umat islam

\section{A. Pengertian Akidah dan globalisasi}

Akidah adalah sebuah istilah yang tidak asing lagi bagi umat Islam. Bahkan bisa dibilang pemahaman tentang aqidah adalah landasan dari ajaran Islam. Dalam istilah agama Islam, aqidah juga bisa dimaknai sebagai iman. Menurut Kamus Besar Bahasa Indonesia, aqidah adalah kepercayaan dasar atau keyakinan pokok. Dalam bahasa Arab, aqidah adalah kata yang berasal dari al-'aqdu yang berarti ikatan, at-tautsiiqu yang berarti kepercayaan atau keyakinan yang kuat, al-ihkaamu yang artinya mengokohkan (menetapkan), dan ar-rabthu biquw-wah yang berarti mengikat dengan kuat. Aqidah adalah apa yang diyakini oleh seseorang. Aqidah merupakan perbuatan hati, yaitu kepercayaan hati dan pembenaran terhadap sesuatu.Sementara itu, menurut istilah atau terminologi, aqidah adalah iman yang teguh dan pasti, yang tidak ada keraguan sedikit pun bagi orang yang meyakininya. Jadi, secara bahasa aqidah adalah keyakinan yang kokoh atas sesuatu sehingga tidak ada keraguan yang mengiringinya. Keyakinan ini tentu saja harus sesuai dengan realita agar aqidah yang dimiliki menjadi benar.

Globalisasi adalah proses mendunianya suatu hal sehingga batas antara negara menjadi hilang. Globalisasi didukung oleh berbagai faktor, seperti perkembangan 
teknologi, transportasi, ilmu pengetahuan, telekomunikasi, dan sebagainya yang kemudian berpengaruh pada perubahan berbagai aspek kehidupan dalam masyarakat. Era Globalisasi ditandai dengan kemajuan dalam bidang ilmu pengetahuan dan teknologi. Dampak dari kemajuan tersebut tentunya melahirkan sisi positif sekaligus negatif. Dalam mengatasi dampak negatifnya ini dibutuhkan suatu usaha yang serius untuk mengatasinya. Salah satu usaha untuk menanggulanginya yaitu melalui pendidikan agama. Dalam hal ini penanganan dan penanaman aqidah dan akhlak merupakan salah satu alat untuk mengatasinya, khususnya melalui pendidikan agama Islam yang merupakan tuntutan dan kebutuhan mutlak bagi manusia muslim.

B. Pengaruh Globalisasi terhadap akidah umat muslim masa kini globalisasi telah memengaruhi beberapa keadaan umat Islam sekarang ini, seperti berikut:

\section{Pola pikir yang sekuler}

Globalisasi ternyata ada juga membawa manfaat bagi membuka cakrawala berfikir yang sangat luas dan dinamis, karena semua khazanah keilmuan terbuka lebar dibumi ini serta dapat dikomunikasikan kepada siapa saja melalui email, facebook, internet dan perpustakaan digital. Dimasa kini seorang dosen dan guru akan menyampaikan kuliah atau pelajarannya lewat internet, telecomfrens, sehingga boleh jadi seorang mahasiswa atau pelajar tidak mesti duduk dalam ruangan kuliah, mereka boleh dirumah, warung kopi dan dilapangan terbuka untuk mendengarkan kuliah sang dosen. Belajar diera globalisasi ini pula dapat menimbulkan cara berfikir yang skuler dan lebral, karena semakin derasnya arus berfikir Barat yang sekuler dan lebral itu menebus fikiran, jiwa dan emosi para mahasiswa dan remaja umat Islam. Berfikir sekuler dan liberal, merupakan akibat yang tidak terelakkan dari proses modernisasi bangsa. Sekularisasi tanpa modernisasi tak ubahnya bagaikan seperti mata uang yang tidak mungkin dipisahkan satu sama lain. Oleh karena itu, dalam diskursus ilmu sosial atau sosiologi ada sebuah teori terenal yang mengatakan bahwa, makin maju suatu masyarakat, maka semakin menurun komitmen mereka pada agama. "Maju" disini maksudnya adalah "Modern".

Fenomena budaya dan agama yang berkembang di Barat justru dijadikan contoh oleh sebahagian umat Islam di Indonesia, sehingga mengamalkan ajaran Islam yang bebas dan sekuler. Secara bebas maksudnya adalah yang mengamalkan Islam secara parsial dan menurut hasil pemikiran semata serta mengikuti kehendak sendiri. Dewasa ini ada wacana agama universal yaitu mengamalkan ajaran Islam menurut situasi dan kondisi, sehingga muncul pengamalan shalat menggunakan bahasa Indonesia, melaksanakan haji tidaj mesti ke Makkah sehingga boleh dilakukan di Indonesia.rakaat shalat boleh ditambah dan dikurangi berdasarkan keperluan, dan shalat tidak perlu dikerjakan secara fisik tetapi cukup berzikir (as-shalatu li zikri) hanya dengan eling (ingat) kepada Allah. Terlalu banyak penyimpangan ajaran Islam yang dilakukan oleh sebagian umat Muslim karena terpengaruh oleh budaya barat. 


\section{Memicu radikalisme dan sampalan}

Sekarang ini telah muncul faham radikalisme agama baik dilakukan oleh umat Islam maupun umat non Islam. Faham ini tentu memiliki alasan tersendiri bagi mereka dengan mengatas namakan jihad fi sabilillah dengan tujuan memerangi kejahatan dan oknum pemerintah yang merusak Islam. Alasan ini memang bersumber dari Al quran yang memerintahkan umat Islam berjuang (jihad) dijalan Allah dengan nyawa, dengan harta (Q.S. 9:20). Pada masa Rasulullah Saw. jihad seperti inilah yang dilakukan oleh pejuang Islam dan para sahabat Nabi pada masa itu, dengan musuhnya yang sangat nyata dan jelas yaitu kafir dan musyrikin Quraisy, sehingga mereka mengangkat senjata melakukan perang besar besaran seperti perang Badar, Uhud, Handaq, dan lainnya. Jihad semacam ini wajib dilakukan karena atas perintah Allah Swt. dan Rasul-Nya.

Lebih-lebih lagi di Indonesia yang multi etnik dan agama yang memerlukan kearifan dari umat Islam yang mayoritas, sehingga dapat melindungi dan bekerja sama dengan umat non Islam mesti melindungi umat non Muslim sepanjang mereka tidak mengganggu ajaran Islam dan mengusir umat Islam dari negeri sendiri. Kenyataan ini memang sangat factual terjadi dinegeri ini, yang melecehkan nabi Muhammad Saw dengan karikatur, menghina kehidupannya, menghilangkan beberapa ayat suci Al quran, mempelesetkan ajaran Islam, dan melakukan sinktritisasi. Kristenisasi, Yahudisasi, terhadap umat Islam banyak lagi kejadian spektakuler terhadap umat Islam yang dapat melecehkan Islam. Dalam banyak kasus ini, pemerintah kurang mampu memberikan penyelesaian yang kurang adil dan memuaskan bagi umat Islam, maka tidak heran para militant umat Islam melakukan perlawanan dengan jihad yang mereka pahami sendiri, bahwa menegakkan ajaran Allah dibumu adalah kewajiban agama dan tidak memperdulikan orang lain. Bom Bali misalnya dilakukan para mujahid yang mengatas namakan Muslim karena dipicu oleh kegiatan yang mengarah kepada demoralisasi merusak bangsa. Bom di hotel Mrihot di Jakarta tempo dulu, juga dipicu oleh dendam mereka terhadap Amerika Serikat yang senantiasa mendiskriditkan umat Islam dengan terorisme. Dewasa ini muncul pula gerakan radikal Islam yang bernama Islamic State of Iraq and Syiria (ISIS) yang bertentangan dengan ajaran Islam, semua elemen umat Islam di Indonesia, baik dari kalangan pemerintah, MUI dan organisasi masyarakat Islam melarang keberadaan gerakan ini dapat merusak sendi-sendi kehidupan umat beragama serta merong-rong bangsa Indonesia yaitu pancasila,

UUD1945, Bhineka Tunggal Ika dan NKRI. Meskipun gerakan tersebut ada di Timur Tengah tetapi, gerakan ini dapat memicu radikalisme di Indonesia kerea terdapat puluhan dunia luar yang ditiru dan disikapi oleh sebahagian kecil bangsa Indonesia masa kini.

Selain itu muncul juga secara internal aliran-aliran Islam yang sempalan yang pada awal awala Islam bersumber dari pemahaman teologi yang berbeda sudut pandang sehingga sesama umat Islam saling kafir mengkafirkan. Akibat itu ditambah pula dengan suasana agama serta persoalan hidup yang sangat kompleks yang tidak dapat diatasi oleh ajaran agama, lalu kemudian sedikit demisedikit membentuk aliran baru berupa aliran kepercayaan yang pada mulanya menyerempet kepada ajaran Islam. Munculnya berbagai aliran sampalan ini juga diakibatkan oleh lemehnya pengetahuan 
dasar Ilmu Keislaman (ushuluddin), dimana mereka yang membuat aliran ini biasanya menggunakan pendekatan rasio, dan kepentingan sesaat dari nilai agama yang mereka gunakan.

\section{Sikap mental yang pesimis, anarkis dan a-moral}

Masa kini aktivitas internetan dan facebook telah merambah jauh kewilayah pemikiran, nafsu dan hati manusia, lewat sarana ini mulai mengganggu semangat kerja seseorang, menusuk jiwa anggota rumahtangga sehingga banyak terjadi aktivitas cinta yang berujung kepada selingkuh, hubungan intim dan dapat merusak rumah tangga orang lain. Bagi generasi muda Indonesia saat ini kegiatan internetan dan facebook dimanfaatkan sebagai sumber pengetahuan da rujukan ilmiah dalam studinya. Tetapi efek negatifnya sangat besar bagi kualitas hidup para remaja.

\section{Cara mempertahankan akidah di era globalisasi Cara}

mempertahankan akidah ialah:

- Kembali kepada Allah yang mana di mulai dari diri sendiri, maksudnya kita harus berusaha menjadikan diri agar dekat dengan Allah dengan mengerjakan apa yang di perintahkan Allah dan menjauhkan apa yang dilarang oleh Allah

- Memberikan jam pelajaran dan mengevaluasi pelajaran akidalb Membersihkan kitab-kitab yang merujuk akidah yang salah serta Menolak aqidah yang jahat.

Selanjutnya, tersebarnya nilai-nilai budaya yang melanggar nilai-nilai kesopanan dan budaya bangsa melalui media massa seperti tayangan-tayangan film yang mengandung unsur pornografi yang disiarkan televisi asing yang dapat ditangkap melalui antena parabola atau situs-situs pornografi di internet.

Dalam hal ini, agama memiliki peran penting dalam memfilter dampak negatif yang ditimbulkan dari era globalisasi dewasa ini. Pemahaman yang utuh akan agama tidak hanya sebatas rutinitas ritual semata melainkan tertanam dalam di hati (aqidah) dan diejawantahkan melalui perilaku sehari-hari (akhlak). Dengan kata lain, diperlukan pemahaman dan pengamalan agama yang tepat sekaligus pengamalan secara utuh dan konsisten. Permasalahan yang timbul ialah bagaimana cara memantapkan pemahaman keagamaan yang terefleksi dalam perilaku sehari-hari? Tiada lain ialah melalui pendidikan. Pendidikan di sini yang dimaksud bukan hanya di lembaga pendidikan formal saja, melainkan bisa juga pendidikan dalam keluarga dan masyarakat.

Selain itu, yang lebih penting ialah kehadiran pendidikan pesantren yang secara khusus mempelajari ilmu-ilmu agama. Menghadapi arus globalisasi dengan segala dampak negatifnya, sebaiknya para orang tua menyadari bahwa tidak cukup hanya dibekali pengetahuan umum saja, melainkan juga pengetahuan agama. Oleh karena itu, selain sekolah umum sebaiknya dibarengi dengan sekolah yang berbasis keagaman seperti pesantren. 


\section{Pentingnya akidah di era globalisasi}

Akidah merupakan fondasi utama Bangsa Indonesia menghadapi era globalisasi. Akidah, terutama sangat penting bagi kaum muda, sebagai golongan yang rentan tergoda oleh bujuk rayu ideologi dan gaya hidup yang merugikan. Dengan akidah hidup seseorang tidak akan mudah terombang-ambing oleh keadaan. Disamping itu akidah ibarat kompas dalam hidup kita yang mampu menunjukkan arah yang benar saat kita kebingungan. Ilmu juga menjadi bagian penting dalam menghadapi era globalisasi. Karena iman tanpa diimbangi dengan ilmu, menurut dia, maka tidak akan ada gunanya, dan ilmu juga untuk mengasah kecerdasan. Ia menegaskan, jika iman mengasah hati setiap orang maka ilmu lah yang menyempurnakannya dengan memaksimalkan fungsi kerja otak. Aqidah atau keyakinan merupakan unsur rohani manusia yang paling besar perannya dan paling sering, dan banyak mengeluarkan instruksi kepada anggota jasmani untuk melakukan suatu perbuatan. Aqidah yang benar akan membuahkan aktifitas manusia yang benar, akan tetapi kalau sudah salah, maka perbuatan manusia yang ditimbulkannya menjadi salah pula. Akhlaqul Karimah mempunyai peranan yang penting dalam mewujudkan ketertiban dan keharmonisan aktifitas kehidupan manusia. Oleh karena itu usaha kearah perbaikan akhlak merupakan kebutuhan pokok yang harus dilaksanakan oleh setiap individu, rumah tangga dan masyarakat, bangsa dan Negara. Oleh karena itu aqidah Islam mempunyai peranan yang sangat besar terhadap pendidikan dan perbaikan akhlak manusia agar memiliki akhlak yang mulia. 


\section{BAB III PENUTUP}

\section{A. Kesimpulan}

Akidah yang kuat sangat penting di era globalisasi,di karenakan pengaruh globalisasi sangat banyak yang bertolak belakang dengan ajaran agama islam. Tanpa adanya akidah yang kuat di era globalisasi ini maka keyakinan kita terhadap ALLAH SWT menjadi lemah di karenakan banyaknya pengaruh negative dari globalisasi ini.

\section{B. Saran}

Sebagai generasi muda hendaknya kita senantiasa memperbaiki akidah kita mulai dari sekarang.Karena akidah merupakan fondasi agama kita.

\section{DAFTAR PUSTAKA}

Busyra, Zainudin Ahmad. 2010. Buku Pintar Aqidah Akhlak dan Qur'an-Hadits. Yogyakarta: In azna book.

Ashar, F. (2018). Pengertian Globalisasi, Pengaruh, Dampak Positif dan Negatifnya. Diakses dari : https://informasiana.com/pengertian-globalisasimenurut-ahli/ Abudin Nata, Aqidah Akhlak, Dirjen Binbaga Islam, Jakarta, 1996. 